\title{
A curious lobe
}

Andréa Chabot-Naud ${ }^{1}$, George Rakovich MD², Karine Chagnon MD³, Denise Ouellette $M D^{2}$, Gilles Beauchamp MD²

\begin{abstract}
A Chabot-Naud, G Rakovich, K Chagnon, D Ouellette, G Beauchamp. A curious lobe. Can Respir J 2011;18(2):79-80.

A case of azygos lobe is presented. An azygos lobe is an accessory lobe of the lung that may occasionally be confused with a pathological process such as a bulla, lung abscess or neoplasm. Its pathogenesis is discussed, as are the characteristic $\mathrm{x}$-ray features that enable an accurate diagnosis.
\end{abstract}

\section{Un curieux lobe}

Un cas de lobe azygos est présenté. Un lobe azygos est un lobe accessoire du poumon qui peut parfois être confondu avec un processus pathologique comme une bulle, un abcès pulmonaire ou un néoplasme. Sa pathogenèse est exposée, de même que les caractéristiques radiographiques qui permettent de poser un diagnostic exact.

Key Words: Accessory lobe; Anatomy; Azygos lobe; Lung

\section{CASE PRESENTATION}

48-year-old man underwent a chest $\mathrm{x}$-ray while being treated Ifor a colorectal malignancy. The $x$-ray showed a curvilinear shadow outlining the apex of the right lung (Figure 1). What is the diagnosis?

\section{DISCUSSION}

The lungs are normally divided into five lobes by three main fissures (1). Occasionally, invaginations of the visceral pleura create accessory fissures that separate individual bronchopulmonary segments into accessory lobes (1).

An azygos lobe is found in approximately $0.4 \%$ of patients (2). In contrast to other accessory lobes, the azygos lobe does not correspond to a distinct anatomical bronchopulmonary segment $(1,3)$. It forms during embryogenesis when the precursor of the azygos vein fails to migrate

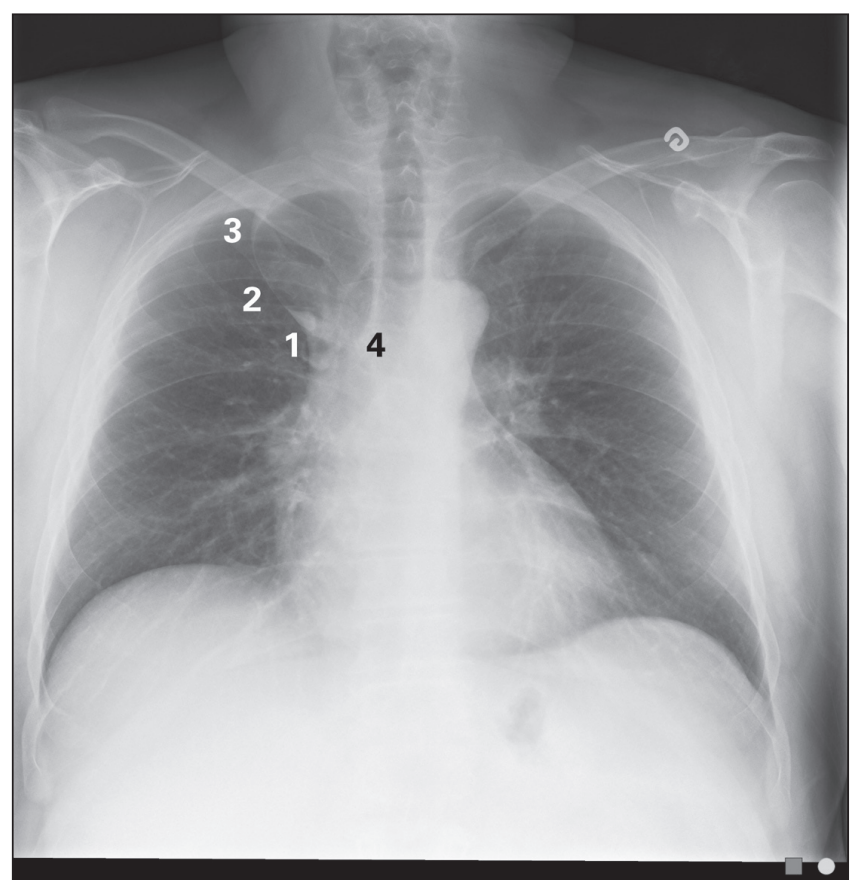

Figure 1) Chest $x$-ray showing a curvilinear shadow spanning the apex of the right lung. 1 Azygous vein. 2 Azygous fissure. 3 Separation of the mesoazygous folds at the chest wall. 4 Tracheobronchial angle to its medial position in the mediastinum, where it normally arches over the origin of the right upper lobe bronchus (1-3). This gives rise to the following characteristics, which are visible on a standard chest $\mathrm{x}$-ray (Figure 1): the laterally displaced azygos vein lies between folds of parietal pleura, also referred to as the mesoazygos, where it assumes a characteristic teardrop shape $(2,3)$; the mesoazygos indents the right upper lobe, thereby creating the accessory (azygos) fissure, which is similar in shape to an inverted comma; the fissure delineates the azygos lobe, located superomedially (1-3); laterally, the pleural folds of the mesoazygos separate before reaching the chest wall, resulting in a radiopaque triangular area $(2,3)$; and medially, the tracheobronchial angle appears empty (2) (Figures 2, 3 and 4).

An azygos lobe may be confused with a pathological air space such as a bulla or abscess $(2,3)$. In addition, the abnormally located azygos vein may be mistaken for a pulmonary nodule, while a consolidated azygos lobe may be confused with a mass (3). An understanding of the pathogenesis and characteristic $x$-ray features of the azygos lobe will enable an accurate diagnosis in most cases (1-3). If the $x$-ray findings are equivocal, computed tomography will be diagnostic (3).

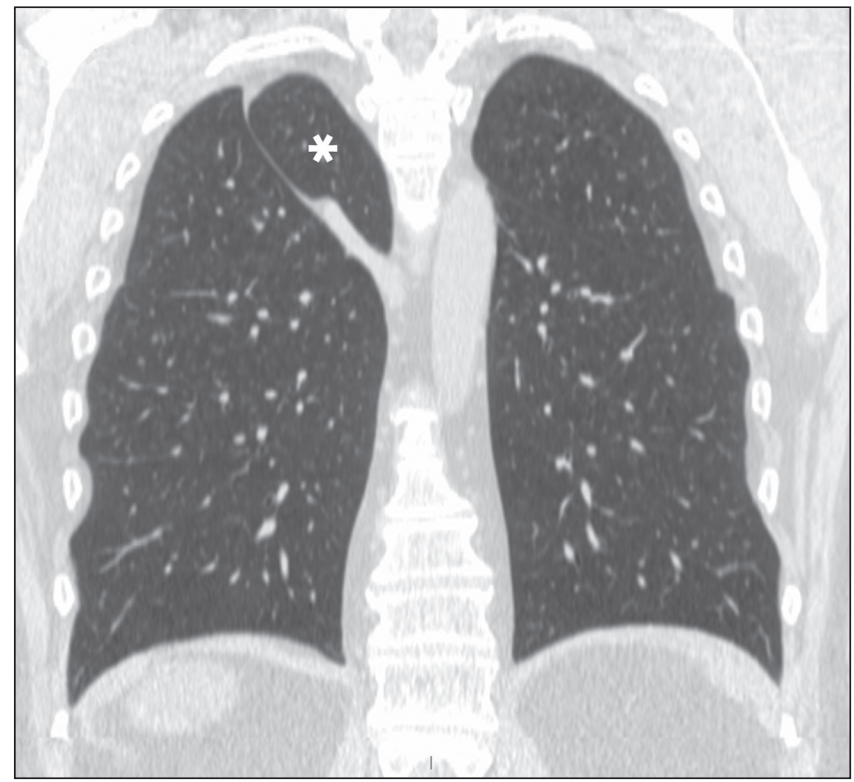

Figure 2) Computed tomography of the chest (coronal reconstruction) showing the azygos fissure outlining the azygos lobe (asterisk)

${ }^{1}$ Faculty of Medicine, University of Montreal; ${ }^{2}$ Division of Thoracic Surgery; ${ }^{3}$ Division of Pneumology, Hôpital Maisonneuve-Rosemont, Montreal, Quebec

Correspondence: Dr George Rakovich, Division of Thoracic Surgery, Hôpital Maisonneuve-Rosemont, 5415 boulevard de l'Assomption, Montreal, Quebec H1T 2M4. Telephone 514-252-3822, fax 514-252-3894, e-mail george.rakovich@umontreal.ca 


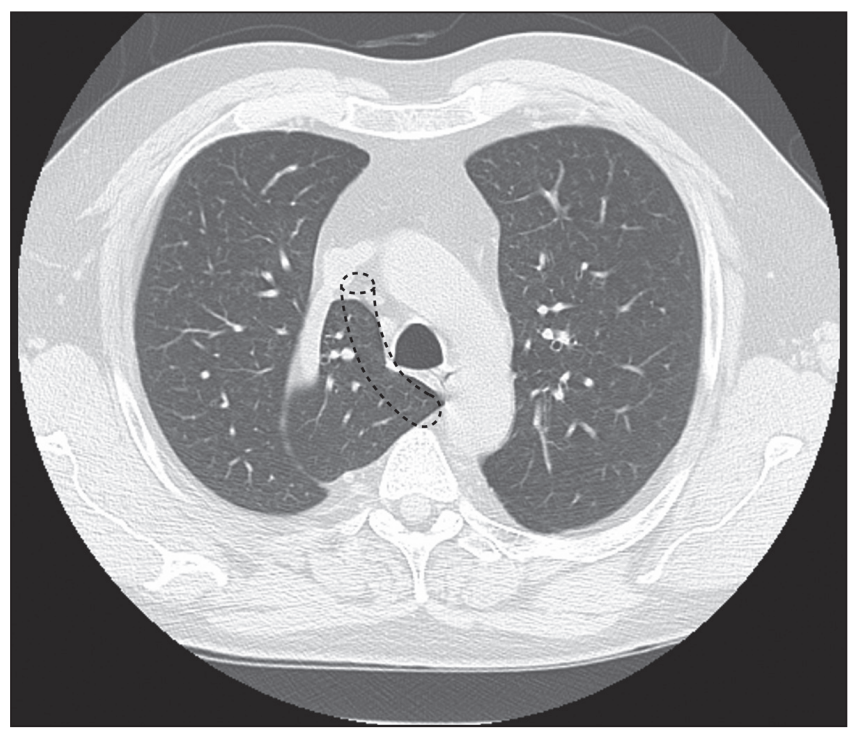

Figure 3) Computed tomography scan of the chest showing the azygos fissure and abnormally located azygos vein. The normal course of the azygos vein is highlighted

\section{REFERENCES}

1. Shields TW, Locicero J, Reed CE, Feins RH. General thoracic surgery, 7th edn. Chicago: Lippincott Williams and Wilkins, 2009:72-3.

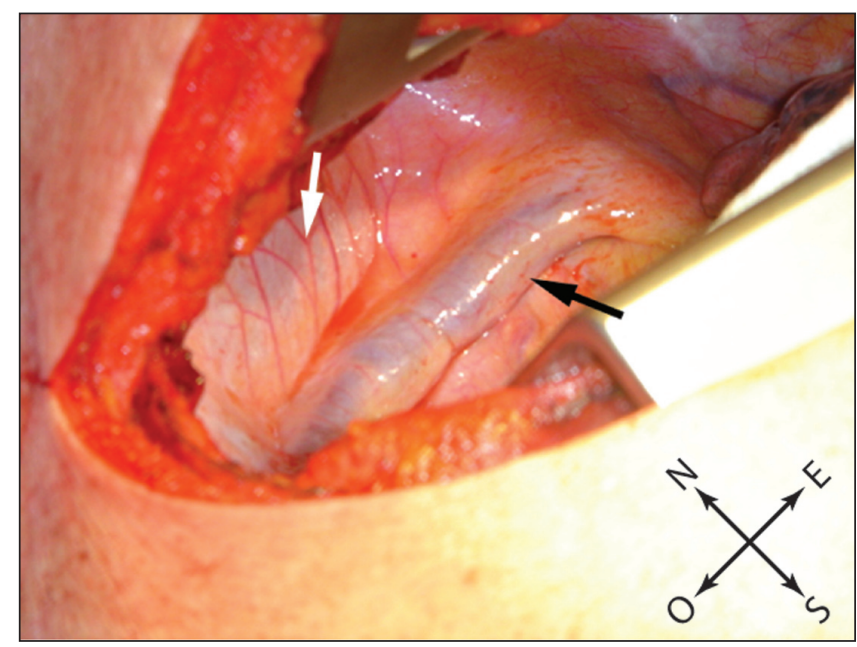

Figure 4) Additional example of an azygos lobe. In this lung cancer patient, the right upper lobe has been removed; the azygos vein (black arrow) and mesoazygos (white arrow) are clearly visible. (The compass is oriented cephalad - the mediastinum is in the background)

2. Felson B. The azygos lobe: Its variation in health and disease. Semin Roentgenol 1989;24:56-66.

3. Caceres J, Mata JM, Andreu J. The azygos lobe: Normal variants that may simulate disease. Eur J Radiol 1998;27:15-20. 


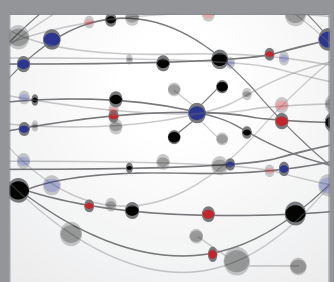

The Scientific World Journal
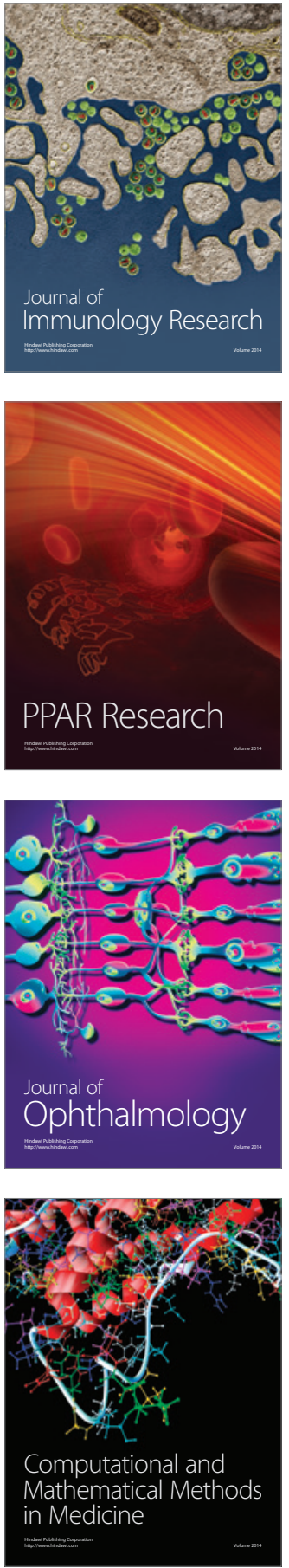

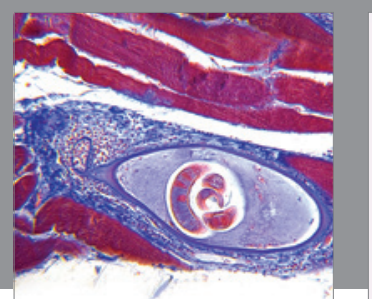

Gastroenterology Research and Practice

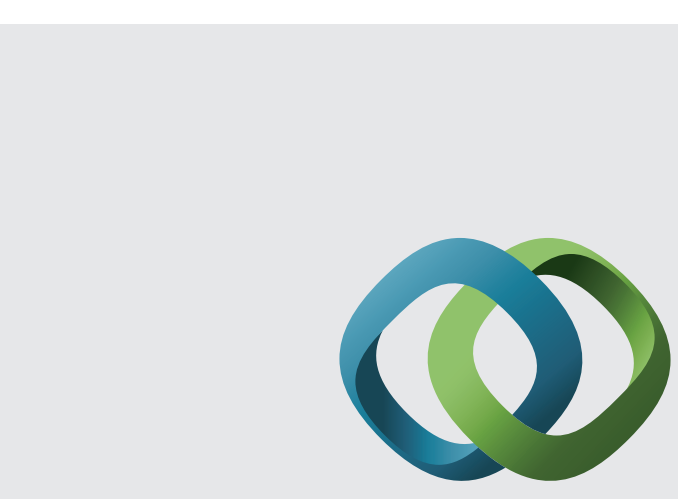

\section{Hindawi}

Submit your manuscripts at

http://www.hindawi.com
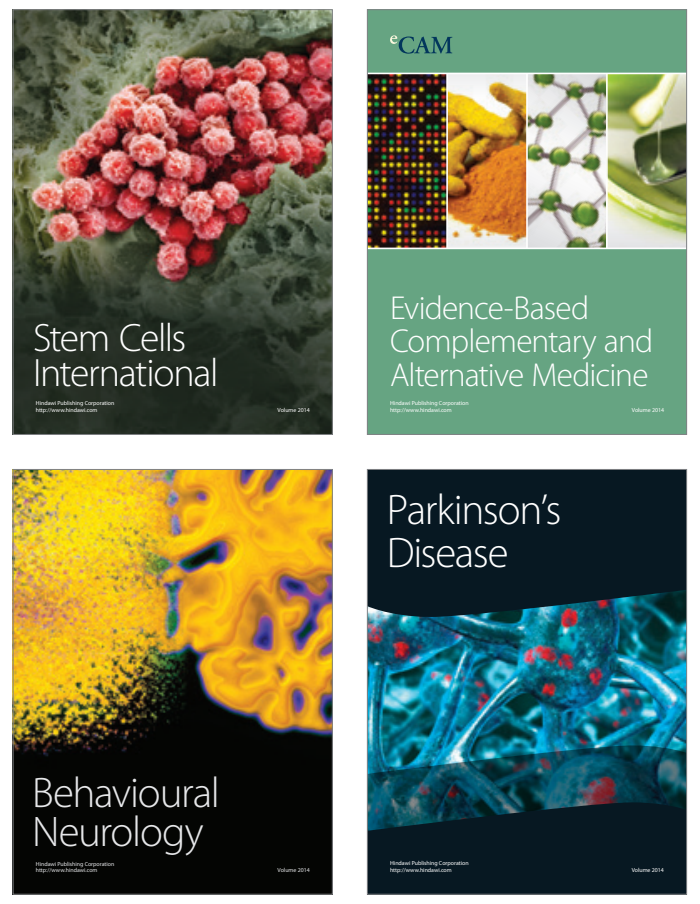
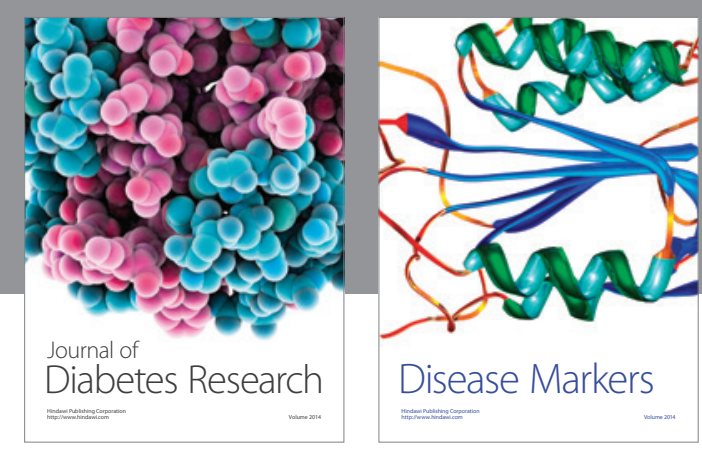

Disease Markers
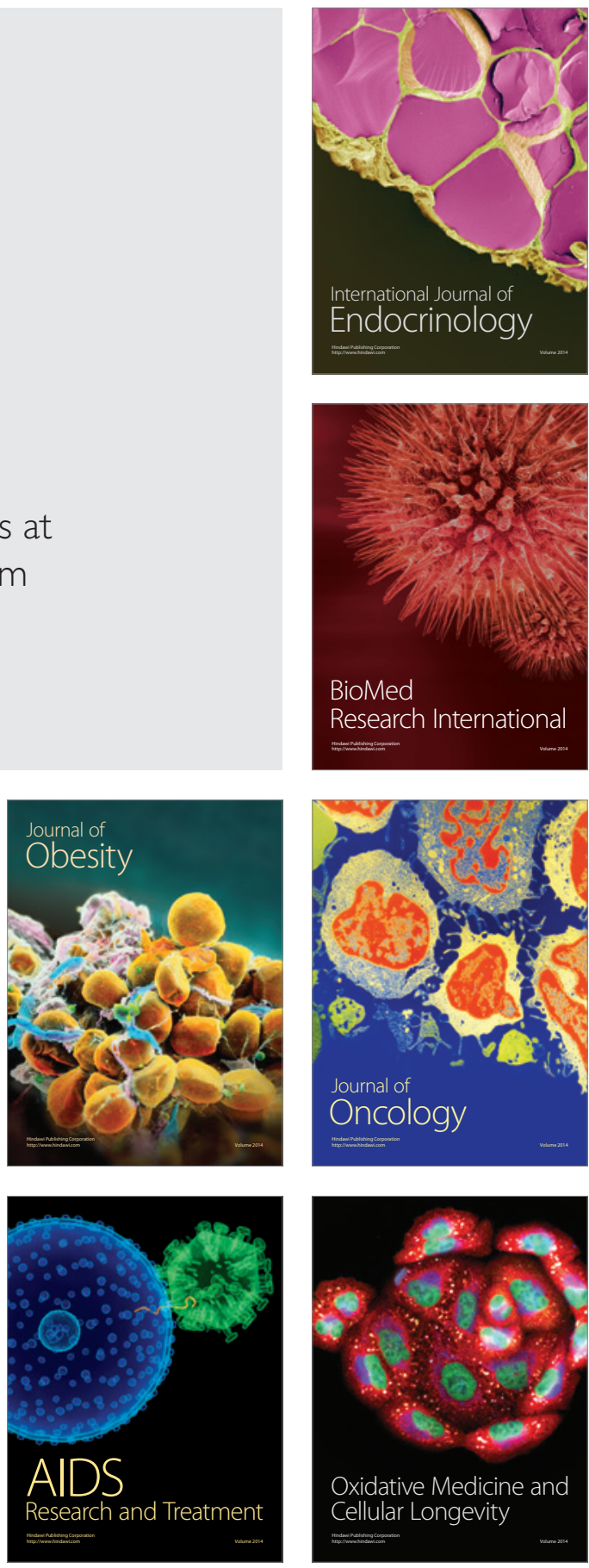